\title{
POLÍTICA Y CONFLICTOS \\ LINGÜÍSTICOS EN EL ESTADO ESPAÑOL
}

\author{
Albert Branchadell
}

\author{
Universitat Autònoma de Barcelona
}

* Con posterioridad a la presentación de esta ponencia, el Gobierno gallego promulgó el «Decreto 79/2010, para o plurilingüismo no ensino non universitario de Galicia", que incide directamente en uno de los temas tratados aquí. El autor ha renunciado al ejercicio de incorporar a su texto un Decreto que todavía no existía "at the time of writing». En todo caso, cuando llegue el momento bastará tener en cuenta que este Decreto no es una apuesta por la libertad de elección de la lengua vehicular. Por la misma razón, en el texto no aparecen referencias a la sentencia del Tribunal Constitucional sobre el Estatuto de Autonomía de Cataluña de 28 de junio de 2010. Cuando llegue el momento bastará considerar que en esta sentencia el TC se alinea con la tesis de que en una comunidad autónoma bilingüe el grado de oficialidad de la lengua propia no puede ser superior al grado de oficialidad del castellano. 



\section{INTRODUCCIÓN}

El objeto de esta ponencia, de acuerdo con (mi interpretación de) el título propuesto por los coordinadores del Seminario, es reflexionar sobre la política (lingüística) y los conflictos lingüísticos que supuestamente forman parte de la situación sociolingüística actual en España. Más concretamente, en esta ponencia me propongo hacer tres cosas. En primer lugar, quisiera revisar brevemente el propio concepto de conflicto lingüístico. Mi intención es señalar que la definición puesta en circulación en España por Lluís V. Aracil en los años sesenta del siglo XX es inservible (por razones teóricas, empíricas y también políticas), por lo que es necesario acudir a definiciones de otro tipo. Mi propósito es partir de una noción del conflicto lingüístico no como enfrentamiento entre comunidades lingüísticas sino como desacuerdo entre actores políticos sobre el estatus relativo de las lenguas. En segundo lugar, me interesaría identificar cuáles son las principales áreas de desacuerdo surgidas después del consenso lingüístico alcanzado en la Constitución de 1978. Creo que en este periodo las dos grandes áreas de desacuerdo en materia de política lingüística se encuentran en la educación (la cuestión de la lengua vehicular) y la Administración pública (la doble cuestión de los usos lingüísticos y del requisito lingüístico). Mi intención es describir con cierto detalle la primera área ${ }^{1}$ y dejar simplemente esbozada la segunda, entendiendo que ambas ilustran igualmente la confrontación de dos interpretaciones distintas de la (co)oficialidad lingüística prevista por la Constitución. Naturalmente, hay otras controversias importantes, por ejemplo la que se refiere al posible uso obligatorio de las lenguas propias distintas del castellano en el comercio o en los medios de comunicación privados, pero por un lado no están

\footnotetext{
${ }^{1}$ La razón está en lo que dice, referido a Galicia pero extrapolable a toda España, mi colega Xaime Subiela: «Boa parte da política lingüística destes anos, sobre todo nas súas dimensións máis conflitivas, vai ter que ver coa xestión das dúas linguas oficiais no ensino básico e medio» (2002: 160).
} 
tan desarrolladas y por otro lado desbordan el epígrafe de la (co)oficialidad lingüística que cobija a las otras dos. En tercer lugar, me gustaría terminar con otra breve reflexión sobre la posibilidad de pacificar las controversias identificadas; en otras palabras, me gustaría otear qué posibilidades de consenso se presentan en el horizonte. En este punto sostendré que para que el consenso sea posible los actores políticos en situación de desacuerdo deberían ceder, pero no tanto en el sentido de aceptar las tesis de sus adversarios como en el de cambiar el punto de vista que fundamenta las suyas. En general, no es lógico esperar que las controversias cesen en relación a la política lingüística mientras permanecen (y son deseables: ¡eso es de la democracia!) en cualquier otra área, sea la política fiscal, la social, la educativa o la cultural. Pero tampoco es lógico pensar que en política lingüística es imposible llegar a acuerdos mientras sí que lo es en cualquier otra área.

\section{1. ¿CONFLICTO LINGÜÍSTICO?}

Sin duda, para reflexionar bien sobre los conflictos lingüísticos (en España o donde sea) lo primero que hay que hacer es definir el concepto de conflicto lingüístico. En esta tarea habría que remontarse a los trabajos de Lluís V. Aracil. Cito aquí un trabajo suyo de 1967 :

Las funciones sociales del lenguaje y las funciones lingüísticas de la sociedad forman un círculo funcional —un circuito de realimentación-, que puede funcionar de dos maneras. La respuesta al desajuste puede consistir en corregirlo o en multiplicarlo en forma de círculo vicioso. Llamo al primero proceso [de] normalización. El segundo conduce virtualmente a la extinción del sistema lingüístico. El conflicto lingüístico es aquella coyuntura en que surge el dilema entre estas dos opciones últimas (Vallverdú, 1981: 29s)².

El primer argumento contra esta definición es de tipo teórico. La definición de Aracil no concuerda con la que se consideraría definición estándar en lo que podríamos llamar sociolingüística internacional. En la sociolingüística interna-

${ }^{2}$ La cita es de «Sociolingüística: un nou enfocament», un texto multicopiado de 1967. 
cional el conflicto lingüístico no se plantea habitualmente en términos del dilema «extinción o normalización». Véase como ejemplo la definición de Trudgill (2003: 73):

In multilingual situations, social strife and other problems which arise where the needs or rights or wishes of different groups speaking different languages conflict. The term is more especially applied to disagreements that are specifically to do with language, such as which language is to be the official language in a particular area; which language children are to receive their education in; and which language is to be used in the courts [...]. Language planning activities are often directed at solving problems arising out of language conflict.

En segundo lugar, la definición de Aracil y compañía resulta inadecuada en términos empíricos. En el mundo se observa un amplio número de «conflictos» lingüísticos de larga duración, que no se han resuelto ni parece que vayan a resolverse de acuerdo con el dilema "extinción o normalización». Simplemente, más allá de este dilema hay otros modus vivendi posibles. Aquí me gustaría simpatizar con algo que decía Henrique Monteagudo en un interesante libro de debate sobre la normalización lingüística en Galicia (2002: 34):

Unha situación de bilingüismo social é de por si insostible, e desemboca necesariamente na prevalencia dun dos idiomas en concorrencia e na desaparición do outro. Iso é outro mito, e por tanto non existe sociolingüística capaz de probalo cientificamente.

En tercer lugar, el dilema «extinción o normalización» es cuando menos políticamente inoportuno. Sigo citando (y subscribiendo) a Henrique Monteagudo (2002: 35):

Por outra banda, por moito que se diga o contrario, non se ve como sería posible facer desaparecer da comunicación pública o castelán se non fose mediante políticas autoritarias. ¿̨énsase atraer cara ó campo da normalización lingüística ós numerosos castelán falantes de Galicia propóndolles un modelo sociolingüístico que implicaría pura e sinxelamente unha forte discriminación negativa deles mesmos? 
Resumiendo: el dilema «extinción o normalización» (es decir, extinción de la «lengua dominada» o de la «lengua dominante») no es canónico en la sociolingüística internacional, tampoco parece empíricamente adecuado y, finalmente, no resulta políticamente (por no decir «moralmente») plausible.

La sociolingüística internacional no solo no plantea el conflicto lingüístico como un dilema entre la extinción y la normalización de una lengua; sino que también tiende a concebir el conflicto no entre lenguas sino entre hablantes de lenguas o grupos lingüísticos (es decir, el conflicto lingüístico viene a plantearse como una variante del conflicto étnico).

Para terminar de aclarar sobre qué vamos a discutir, en este punto me interesaría sostener que en España (ni históricamente ni ahora) no podemos hablar de conflicto lingüístico como conflicto étnico que enfrente a unos grupos lingüísticos con otros. Está claro que hasta 1978, y con el breve paréntesis de la II República, España siguió la senda del monolingüismo oficial que siguieron tantos países europeos desde la Revolución Francesa, pero no existen realmente episodios de "confrontación social manifesta» (al decir de Subiela, 2002: 160) entre los hablantes de la única lengua oficial y los de las demás lenguas. En este sentido, me gustaría sostener que de 1978 para acá en España no es posible hablar realmente de una politización de las diferencias lingüísticas y más concretamente que no es posible hablar de una alineación de los grupos lingüísticos con partidos políticos determinados. (Naturalmente la no politización de un cleavage lingüístico es compatible con la instrumentalización oportunista de las lenguas por parte de los actores políticos, de la cual veremos alguna muestra en esta ponencia).

En esta sección hemos considerado inservible el concepto de conflicto de Aracil basado en el enfrentamiento entre lenguas y el dilema «extinción o normalización». Pero ahora vemos que el concepto de conflicto entendido como enfrentamiento entre grupos lingüísticos tampoco es adecuado. En lo que queda de ponencia vamos a retomar la idea de Trudgill según la cual «the term is more especially applied to disagreements that are specifically to do with language». Nuestra misión en el siguiente punto será identificar los principales desacuerdos de este tipo que se dan hoy en España. 


\section{IDENTIFICAR DESACUERDOS}

\subsection{Introducción}

Antes de entrar en materia vamos a hacer una breve reflexión sobre el régimen lingüístico introducido por la Constitución española de 1978 y sobre las alternativas que se plantean a este régimen. Este será el marco en el que analizaremos nuestros desacuerdos.

En la siguiente tabla vamos a representar los diferentes regímenes lingüísticos posibles en un estado federal o autonómico (por ejemplo, España) con unidades subestatales que disponen de una lengua propia (por ejemplo, Galicia). Un estado puede tener una o más lenguas oficiales, lo mismo que una unidad subestatal. Esto permite cuatro posibilidades lógicas (Vid. tabla 1).

- Tabla 1. Tipología de regímenes lingüísticos (I)

\begin{tabular}{|c|c|c|c|c|c|}
\hline & \multicolumn{4}{|c|}{ UNIDAD SUBESTATAL } \\
\hline & & & 1 & & $n>1$ \\
\hline \multirow{2}{*}{ ESTADO } & 1 & & $(1,1)$ & 2 & $(1, n)$ \\
\hline & $n>1$ & & $(n, 1)$ & \begin{tabular}{|l|}
4 \\
\end{tabular} & $(n, n)$ \\
\hline
\end{tabular}

La Constitución de 1978 mantuvo el castellano como única lengua oficial de (todo el territorio de) el estado pero revolucionó el secular monolingüismo oficial español con la introducción de la oficialidad de las «demás lenguas españolas» en las comunidades autónomas respectivas. De esta manera, entre los cuatro regímenes lingüísticos posibles se optó por el de la casilla 2 . El estado tiene una sola lengua oficial (el castellano [ES]) y las comunidades autónomas relevantes tienen dos (el castellano y la lengua propia [LP] de la comunidad) (Vid. tabla 2).

- Tabla 2. Tipología de regímenes lingüísticos (II)

\begin{tabular}{|c|c|c|c|c|}
\hline & \multicolumn{3}{|c|}{ COMUNIDAD AUTÓNOMA } \\
\hline & & & 1 & $n>1$ \\
\hline \multirow{2}{*}{ ESTADO } & 1 & & (ES, LP) & 2 (ES, ES+LP) \\
\hline & $n>1$ & & (ES+LP, LP) & $4{ }^{(E S+L P, E S+L P)}$ \\
\hline
\end{tabular}


El modelo de la casilla 2 (ES, ES+LP) sigue gozando de un amplio consenso. Si dejamos a un lado la defensa ampliamente testimonial del modelo de la casilla 4 (ES+LP, ES+LP) por parte de determinados actores políticos, las grandes controversias que se han planteado desde 1978 para acá tienen más que ver con el grado relativo de oficialidad de ES y LP dentro de las comunidades autónomas que con la posible oficialidad de LP en las instituciones del estado. Simplificando mucho, podríamos decir que a lo largo de estos 30 años se han contrapuesto dos interpretaciones de la doble oficialidad en las comunidades autónomas: según una interpretación, el grado de oficialidad de LP debe ser superior al grado de oficialidad de ES; según la otra interpretación, el grado de oficialidad de LP debe ser idéntico al grado de oficialidad de ES - lo que, a causa de las desigualdades históricas entre ES y LP, puede acarrear de hecho un grado inferior de oficialidad. Naturalmente, estas interpretaciones, llevadas a sus extremos, suponen el abandono del modelo de la casilla 2 (ES, ES+LP). En un caso produciría un deslizamiento hacia la casilla 1 (ES, LP) (es decir, hacia una situación anticonstitucional de desoficialización del castellano en las comunidades autónomas relevantes); en el otro, un deslizamiento hacia fuera de la tabla (ES) (es decir, hacia una situación preconstitucional de desoficialización de LP en las comunidades autónomas relevantes).

La Constitución, como hemos dicho, prevé la oficialidad de las «demás lenguas españolas» en las respectivas comunidades autónomas de acuerdo con sus estatutos de autonomía pero no da más detalles sobre las consecuencias de esa oficialidad. Los estatutos de autonomía dieron un primer paso al declarar las «demás lenguas españolas» lenguas propias de sus respectivos territorios, aunque por lo demás dispensaban un trato simétrico a esas lenguas y al castellano. En particular, en los estatutos se reconocía que a) todo el mundo tiene el derecho de conocer y usar ambas lenguas oficiales y se establecía que b) debe garantizarse el uso normal y oficial de ambas lenguas.

Fueron las leyes de normalización lingüística (especialmente la de Cataluña) las que empezaron a extraer consecuencias de la declaración de propiedad y, con ello, a fundamentar jurídicamente una política lingüística de tratamiento no simétrico de las dos lenguas oficiales. Vamos a comprobarlo para el caso específico de la educación.

Por lo que respecta a Cataluña, véase el artículo 14 de la Ley de normalización lingüística en Cataluña ${ }^{3}$ :

${ }^{3}$ Llei 7/1983, de 18 d'abril, de normalització lingüística a Catalunya. 
1. El català, com a llengua pròpia de Catalunya, ho és també de l'ensenyament en tots els nivells educatius.

Como excepción a este principio, la Ley reconoce el derecho de los niños a recibir «la primera enseñanza» en su lengua habitual (castellano o catalán):

2. Els infants tenen dret a rebre el primer ensenyament en llur llengua habitual, ja sigui aquesta el català o el castellà. L'Administració ha de garantir aquest dret i posar els mitjans necessaris per a fer-lo efectiu. Els pares o els tutors poden exercir-lo en nom de llurs fills instant que s'apliqui.

Por lo demás, se establece la obligatoriedad de enseñar el catalán (y el castellano) en todos los niveles y se fija el objetivo del bilingüismo terminal:

3. La llengua catalana i la llengua castellana han d'ésser ensenyades obligatòriament a tots els nivells i els graus de l'ensenyament no universitari.

4. Tots els infants de Catalunya, qualsevol que sigui llur llengua habitual en iniciar l'ensenyament, han de poder utilitzar normalment i correctament el català i el castellà al final dels estudis bàsics.

A pesar de la contundencia del artículo 14.1, en términos de lengua vehicular la Ley no establecía nada, más allá de la obligación de la Administración de tomar las medidas convenientes para que «la llengua catalana sigui emprada progressivament a mesura que tots els alumnes la vagin dominant». En todo caso, a partir de la premisa del catalán como lengua propia de la educación, la legislación posterior a esta primera Ley de normalización terminó convirtiendo al catalán en (única) lengua vehicular de toda la enseñanza no universitaria. Lo establecido en dos decretos de $1992^{4}$ fue elevado a rango de ley en 1998 y a rango estatutario en 2006. Véase el artículo 21 de la Ley de política lingüística $:$ «1. El català s'ha d'utilitzar normalment com a llengua vehicular i d'aprenentatge en l'ensenyament no universitari».

\footnotetext{
${ }^{4}$ Decrets 95/1992 i 96/1992, de 28 d'abril, pels quals s'estableix l'ordenació curricular de l'educació primària i l'ordenació dels ensenyaments de l'educació secundària obligatòria.

${ }^{5}$ Llei 1/1998, de 7 de gener, de política lingüística.
} 
Y también el artículo 6 del Estatuto de Autonomía de Cataluña ${ }^{6}:$ «1. La llengua pròpia de Catalunya és el català. Com a tal, el català és la llengua d'ús normal i preferent de les administracions públiques i dels mitjans de comunicació públics de Catalunya, i és també la llengua normalment emprada com a vehicular i d'aprenentatge en l'ensenyament».

La legislación gallega y, especialmente, la vasca partieron de premisas distintas. El artículo 15 de la Ley básica de normalización del uso del euskera reza asî́: «Se reconoce a todo alumno el derecho de recibir la enseñanza tanto en euskera como en castellano en los diversos niveles educativos».

A partir de ahí se erigió un sistema de separatismo lingüístico electivo según la terminología de Antoni Milian. No fue hasta el Decreto 175/2007 que el Departamento de Educación vasco intentó abandonar este modelo a favor de un modelo "catalán» 8 .

En el caso de Galicia, la Ley ${ }^{9}$ es muy parecida a la catalana, excepto en un punto importante: el gallego solo es lengua «oficial» (no propia) de la educación (Vid. tabla 3).

- Tabla 3. Comparación entre las leyes de normalización de Galicia y Cataluña

\section{Lei $3 / 1983$}

12.1. O galego, como lingua propia de Galicia, é tamén lingua oficial no ensino en todos os niveis educativos.

13.1. Os nenos teñen dereito a recibir o primeiro ensino na súa lingua materna. $\mathrm{O}$ Goberno Galego arbitrará as medidas necesarias para facer efectivo este dereito.

\section{Lei $7 / 1983$}

14.1. El català, com a llengua pròpia de Catalunya, ho és també de l'ensenyament en tots els nivells educatius.

14.2. Els infants tenen dret a rebre el primer ensenyament en llur llengua habitual, ja sigui aquesta el català o el castellà. L'Administració ha de garantir aquest dret i posar els mitjans necessaris per a ferlo efectiu. Els pares o els tutors poden exercir-lo en nom de llurs fills instant que s'apliqui.

\footnotetext{
${ }^{6}$ Llei orgànica 6/2006, de 19 de juliol, de reforma de l'Estatut d'autonomia de Catalunya.

${ }^{7}$ Ley 10/1982, de 24 de noviembre, básica de normalización del uso del euskera.

${ }^{8}$ Decreto 175/2007, de 16 de octubre, por el que se establece el currículo de la Educación Básica y se implanta en la Comunidad Autónoma del País Vasco.

${ }^{9}$ Lei 3/1983, do 15 de xuño, de normalización lingüística.
} 
Lei 3/1983

13.2. As autoridades educativas da Comunidade Autónoma arbitrarán as medidas encamiñadas a promover o uso progresivo do galego no ensino.

13.3. Os alumnos non poderán ser separados en centros diferentes por razóns da lingua. Tamén se evitará, a non ser que con carácter excepcional as necesidades pedagóxicas así o aconsellaren, a separación en aulas diferentes. 14.1. A lingua galega é materia de estudo obrigatorio en todos os niveis educativos non universitarios. Garantirase o uso efectivo deste dereito en todos os centros públicos e privados.

14.3. As autoridades educativas da Comunidade Autónoma garantirán que ao remate dos ciclos en que o ensino do galego é obrigatorio, os alumnos coñezan este, nos seus niveis oral e escrito, en igualdade co castelán.
Lei 3/1983

14.5. L'administració ha de prendre les mesures convenients perquè: [...] b) la llengua catalana sigui emprada progressivament a mesura que tots els alumnes la vagin dominant.

14.5. L'administració ha de prendre les mesures convenients perquè: a) els alumnes no siguin separats en centres diferents per raons de llengua [...].

14.3. La llengua catalana i la llengua castellana han d'ésser ensenyades obligatòriament a tots els nivells i els graus de l'ensenyament no universitari.

14.4. Tots els infants de Catalunya, qualsevol que sigui llur llengua habitual en iniciar l'ensenyament, han de poder utilitzar normalment i correctament el català i el castellà al final dels estudis bàsics.

Posteriormente, Galicia también evolucionó hacia el modelo «catalán». El Decreto 247/1995 introdujo el uso del gallego como lengua vehicular (no exclusiva) para todos los alumnos ${ }^{10}$ :

4.3. No segundo e no terceiro ciclos de educación primaria impartiranse en galego dúas áreas de coñecemento, cando menos, sendo unha delas a área de coñecemento do medio natural, social e cultural.

10 Decreto 247/1995, do 14 de setembro, polo que se desenvolve a Lei 3/1983, de normalización lingüística, para a súa aplicación ao ensino en lingua galega nas ensinanzas de réxime xeral impartidas nos diferentes niveis non universitarios. 
5.1. Na educación secundaria obrigatoria impartirase en galego a área de ciencias sociais (xeografía e historia) e a área de ciencias da natureza.

5.2. Das materias optativas impartiranse en galego as de ciencias medioambientais e da saúde e, se é o caso, a optativa ofertada polo centro.

6.1. No primeiro curso de bacharelato impartirase en lingua galega como materia común a filosofía e como materias específicas de modalidade as seguintes: tecnoloxía industrial I (bacharelato de tecnoloxía); bioloxía e xeoloxía (bacharelato de ciencias da natureza e da saúde); historia do mundo contemporáneo (bacharelato de humanidades e ciencias sociais); debuxo técnico (bacharelato de artes).

6.2. No segundo curso de bacharelato o alumnado recibirá o ensino en galego de historia, como materia común, e como materias específicas de modalidade: debuxo técnico, tecnoloxía industrial (bacharelato de tecnoloxía); ciencias da terra e medioambientais, debuxo técnico (bacharelato de ciencias da natureza e da saúde); xeografía, historia da arte, historia da filosofía (bacharelato de humanidades e ciencias sociais); historia da arte (bacharelato de artes).

6.3. Así mesmo serán impartidas en galego as seguintes materias optativas: ética e filosofía do dereito, introducción ás ciencias políticas e socioloxía e historia e xeografía de Galicia.

A continuación, el Decreto 124/2007 dio una vuelta de tuerca a esta vehicularización del gallego ${ }^{11}$ :

8. En toda a etapa da educación primaria garantirase o cumprimento do establecido para esta etapa no Plan xeral de normalización da lingua galega aprobado polo Parlamento de Galicia o 21 de setembro de 2004 que se inclúe como anexo a este decreto. Impartiranse obrigatoriamente en galego as áreas de matemáticas, coñecemento do medio natural, social e cultural e educación para a cidadanía e dereitos humanos, garantindo a competencia lingüística propia do nivel nas dúas linguas oficiais da comunidade autónoma.

9.1. Na educación secundaria obrigatoria impartiranse en galego as seguintes materias: ciencias da natureza, ciencias sociais, xeografía e historia, matemáticas e educación para a cida-

${ }^{11}$ Decreto 124/2007, do 28 de xuño, polo que se regula o uso e a promoción do galego no sistema educativo. 
danía. Cando a materia de ciencias da natureza se desdobre en bioloxía e xeoloxía, por un lado, e física e química, por outro, ambas as dúas materias impartiranse en galego.

9.2. Ademais das materias establecidas na epígrafe anterior, o claustro completará o número de materias, excluída a materia que a Lei orgánica de educación determina de carácter voluntario para o alumnado, que garantan o cumprimento do establecido para esta etapa no Plan xeral da normalización da lingua galega aprobado polo Parlamento de Galicia o 21 de setembro de 2004 que se inclúe como anexo a este decreto.

9.3. A educación secundaria obrigatoria proporcionaralle a todo o alumnado unha boa competencia nas dúas linguas oficiais que repercuta de forma positiva no seu uso.

10. No bacharelato, o alumnado recibirá, polo menos, o cincuenta por cento da súa docencia en galego, nos termos establecidos para esta etapa no Plan xeral de normalización da lingua galega aprobado polo Parlamento de Galicia o 21 de setembro de 2004 que se inclúe como anexo a este decreto para alcanzar a competencia lingüística propia do nivel en ambas as dúas linguas.

Hasta aquí, pues, hemos comprobado, usando el caso de la educación, que la interpretación que ha prevalecido dentro de las comunidades autónomas es la primera que señalábamos («el grado de oficialidad de LP debe ser superior al grado de oficialidad de ES»). Típicamente, las controversias de las que vamos a tratar aquí han sido promovidas por sectores contrarios a este desequilibrio a favor de la LP que encarna la segunda de las interpretaciones («el grado de oficialidad de LP debe ser idéntico al grado de oficialidad de ES»). Naturalmente, en este debate discursivo (mucho más que en la realidad empírica) es posible identificar los deslizamientos que señalábamos. Algunos defensores de la primera interpretación acusan a los de la segunda de perseguir la desoficialización de LP o incluso directamente su desaparición; algunos defensores de la segunda interpretación acusan a los de la primera de perseguir la desoficialización de ES o incluso directamente su desaparición. Detrás de estas imputaciones cruzadas está el fenómeno que acertadamente denuncia F. J. García Marcos: «la convicción de que el monolingüismo [...] es la única solución [...] para resolver el contacto de lenguas» (2008: 122) (Vid. tabla 4). 
- Tabla 4. Interpretaciones de la (co)oficialidad dentro de las comunidades autónomas

\begin{tabular}{lll}
\hline & $\begin{array}{l}\text { Posición defendida por cada } \\
\text { interpretación }\end{array}$ & $\begin{array}{l}\text { Posición imputada por la } \\
\text { otra interpretación }\end{array}$ \\
\hline 1 & LP > ES & $\begin{array}{l}\text { Monolingüismo LP. Versión } \\
\text { extrema: lingüicidio de ES }\end{array}$ \\
\hline $2 \quad$ LP = ES & $\begin{array}{l}\text { Monolingüismo ES. Versión } \\
\text { extrema: lingüicidio de LP }\end{array}$ \\
\hline
\end{tabular}

En lo que sigue vamos a evitar estas imputaciones, pero sí que identificaremos algún caso en que tras un aparente LP = ES lo que se postula de hecho es ES > LP.

\subsection{El caso de la enseñanza no universitaria}

Como hemos visto, las políticas lingüísticas desarrolladas en el ámbito de la enseñanza no universitaria por Cataluña, el País Vasco y Galicia tienen un aire de familia. Las tres han apuntado, apuntan o han consumado un modelo en que la lengua propia de la comunidad autónoma es la lengua vehicular de la enseñanza no universitaria.

Por razones obvias, seguramente es en Cataluña donde más se ha desarrollado el debate en torno a esta cuestión. Puede ser instructivo recordar algunos episodios de este debate, también para comprobar que las alternativas que se han propuesto a este modelo no han sido siempre las mismas. Aquí distinguiremos dos grandes alternativas a este modelo: la alternativa 1, que orbita en torno a la libertad de elección de la lengua vehicular por parte de los alumnos, y la alternativa 2 , que orbita en torno al principio de dos lenguas vehiculares para todos los alumnos.

Ya en 1981, cuando solo hacía dos años de la aprobación del Estatuto de Autonomía de Cataluña y Galicia estaba aprobando el suyo, y cuando todavía faltaban dos años para la aprobación de la primera Ley de normalización lingüística en Cataluña, se publicó el llamado «manifiesto de los 2300», firmado, entre otros, por Amando de Miguel y Federico Jiménez Losantos. Es este uno de los primeros documentos de este largo debate en que se defiende el «derecho inalienable a recibir la enseñanza en la propia lengua materna en todos los nive- 
les», y más concretamente «el derecho a recibir la enseñanza en la lengua materna castellana», que según los firmantes «ya empieza hoy a no ser respetado y a ser públicamente contestado». He aquí una manifestación temprana de la alternativa 1.

En 1994, cuando el "proyecto de implantar progresivamente la enseñanza solo en catalán» temido por Federico Jiménez Losantos y compañía ya era una realidad, consagrada por los decretos de 1992, un nuevo manifiesto, titulado «En castellano también, por favor», concretaba esta alternativa 1. Tras reivindicar el derecho de los padres a la «libre elección de la lengua en que sus hijos deben ser educados», proponía tres opciones lingüísticas (obviamente inspiradas en el modelo vasco):

A. Castellano como lengua vehicular y catalán como lengua enseñada desde el primer año de escuela.

B. Bilingüe. La mitad en cada lengua.

C. Catalán como lengua vehicular y castellano como lengua enseñada desde el primer año de escuela.

Sin prestar mucha atención a las implicaciones prácticas de esta propuesta, el manifiesto aseguraba que "padres y jóvenes estudiantes deberían poder disponer de las tres opciones lingüísticas en todos los centros de enseñanza de Cataluña».

La cuestión de la lengua vehicular de la enseñanza hizo su entrada por primera vez en una campaña electoral en las elecciones al Parlamento de Cataluña de 1995. Un ejercicio histórico interesante es comparar el programa electoral del Partido Popular de Cataluña [PPC] de 1992 con el de 1995. En 1992, el apartado de enseñanza del programa electoral no contenía ninguna referencia explícita a la cuestión de las lenguas vehiculares. En cambio, el de 1995 lanza un modelo educativo entero con dos lenguas vehiculares (Vid. tabla 5). 
Tabla 5. Comparación entre los programas electorales del PPC de 1992 y 1995

PPC 1992

Los fundamentos del programa del PP en materia de enseñanza se concretan en:

Principio de libertad: De creación, dirección y elección de centros educativos en todos los niveles.

Derecho prioritario de los padres a la educación de sus hijos con la consiguiente elección del modelo educativo.

Propuestas: Evitar una política lingüística coercitiva. Se garantizará el aprendizaje de las dos lenguas oficiales en Cataluña.
PPC 1995

El PPC sostiene que «l'objectiu fonamental del sistema educatiu bàsic català és que tots els joves de Catalunya assoleixin un domini complet de les dues llengües del país», y en función de este objetivo lanza una modelo «de bilingüismo equilibrado» o «de doble inmersión» que debe contener las dos opciones lingüísticas siguientes:

1. Català com a llengua vehicular i castellà com a llengua ensenyada en l'etapa de l'ensenyament primari, 3-7 anys. Introducció gradual del castellà en determinades àrees fins assolir l'equilibri amb el català, 7-12 anys. I finalment l'ús equilibrat del català i del castellà com a llengües vehiculars dels 12 als 16 anys.

2. Castellà com a llengua vehicular i català com a llengua ensenyada en l'etapa de l'ensenyament primari, 3-7 anys. Introducció gradual del català en determinades àrees fins assolir l'equilibri amb el castellà, 7-12 anys. I finalment, l'ús equilibrat del castellà i del català com a llengües vehiculars dels 12 als 16 anys.

Fíjense que este modelo parece una variante de la alternativa 1 (existe la posibilidad de elegir), pero en realidad da cuerpo a la alternativa 2 (todos los alumnos acaban teniendo dos lenguas vehiculares).

Después de unos cuantos años de relativo abandono del tema lingüístico, el PPC lo retomó tras la aparición (en 2006) de Ciudadanos, un partido político temático centrado en la oposición a la política lingüística de la Generalitat. En este revival el PPC renunció a su modelo de doble inmersión (alternativa 2) y abrazó la libertad de elección (alternativa 1). 
El «efecto Ciudadanos» puede comprobarse con un ejercicio de comparación entre los programas electorales del PPC de los años 2003 y 2006, y también entre este último programa y determinadas iniciativas legislativas emprendidas por el PPC después de las elecciones (Vid. tablas 6 y 7).

- Tabla 6. Comparación entre los programas electorales del PPC de 2003 y 2006

PPC 2003

Educación. Ninguna referencia explícita a las lenguas vehiculares (sí al aprendizaje de lenguas extranjeras y al objetivo de dominar tres lenguas al final de los estudios).
PPC 2006

(antes de las elecciones)

Educación. Ninguna referencia explícita al catalán y al castellano como lenguas vehiculares (sí al aprendizaje de lenguas extranjeras y al objetivo de dominar tres lenguas al final de los estudios). En el marco de un "pacto por el trilingüismo», se incluye la propuesta de «introducir progresivamente el inglés como lengua vehicular en la educación, hasta alcanzar el 20\% de las clases».

Cultura. Se defiende «el dret d'utilitzar qualsevol de les llengües oficials amb plena normalitat $i$ sense traves en tots els àmbits de la vida" pero no hay ninguna referencia a la educación.
Cultura. Aparece como eje de la política lingüística «el derecho a recibir la educación primaria en las dos lenguas oficiales». Al parecer esto se concreta en el cumplimiento del artículo 21.2 de la Ley de política lingüística.
PPC 2006

(después de las elecciones)

Proposición de ley de reforma de la Ley 1/1998, para introducir la libertad de elección de la lengua vehicular, no contemplada en el programa electoral. (El programa solo dice «modificaremos la Ley de política lingüística para suprimir el régimen de sanciones»). 
- Tabla 7. Comparación entre la Ley 1/1998 y la propuesta de reforma del PPC

Texto vigente

20.1. El català, com a llengua pròpia de Catalunya, ho és també de l'ensenyament, en tots els nivells i les modalitats educatius.

20.2. Els centres d'ensenyament de qualsevol grau han de fer del català el vehicle d'expressió normal en llurs activitats docents i administratives, tant les internes com les externes. 21.1. El català s'ha d'utilitzar normalment com a llengua vehicular i d'aprenentatge en l'ensenyament no universitari.
Enmienda PPC 2006

20.1. El Català i el Castellà, com a llengües oficials de Catalunya, ho són també de l'ensenyament, en tots els nivells i modalitats educatives. 20.2. Els pares tenen el dret a escollir en quina llengua volen que els seus fills siguin escolaritzats. L'administració ha de garantir l'exercici efectiu d'aquest dret.

21.1. L'ensenyament no universitari

1. El català i el castellà es podran fer servir com a llengües vehiculars i d'aprenentatge en l'ensenyament no universitari. A tal efecte el pares decidiran en quina llengua volen que siguin escolaritzats els seus fills.

Una duda que plantea esta propuesta es si implica la separación de los alumnos por centros o grupos prohibida por el artículo 21.5 de la misma Ley. En el debate de toma en consideración de esta proposición (6 de febrero de 2007), el portavoz del PP no fue especialmente claro al respecto, y apelaba a una supuesta tercera vía entre la «segregación» que se imputaba a su propuesta y la imposición del «monolingüismo». Mientras en este debate el PPC defendía una propuesta en línea con la alternativa 1 , en el mismo debate el portavoz de Ciudadanos mostró su adhesión a la alternativa 2. Con el añadido del inglés, la propuesta de Ciudadanos retoma la idea de la «doble inmersión» defendida por el Pp en 1995:

Como lo hemos explicado más de una vez, defendemos un modelo trilingüe, donde se respete el derecho a la lengua materna hasta finalizar el primer ciclo de primaria, a partir de la cual habrá una única red escolar, donde el $40 \%$ de las clases se darán en catalán, otro $40 \%$ en castellano y otro $20 \%$ en inglés; siempre en los mismos colegios, sin doble red escolar. 
El "efecto Ciudadanos» que hemos observado en Cataluña en 2006 es un precedente de otro efecto similar registrado a escala española en 2008. Estamos hablando del «efecto UPyD». Del mismo modo que Ciudadanos en 2006, en 2007 Unión Progreso y Democracia nació con un fuerte componente de rechazo a las políticas lingüísticas de las comunidades autónomas españolas con lengua propia.

$\mathrm{El}$ «efecto UPyD» puede comprobarse con un ejercicio de comparación entre los programas electorales del pP de los años 2004 y 2008 (Vid. tabla 8).

- Tabla 8. Comparación entre los programas electorales del Pp de 2004 y 2008

PP 2004

Educación. Ninguna referencia explícita al castellano como lengua vehicular. Se proclama que «La libertad de enseñanza se fundamenta en el derecho que asiste a las familias a que sus hijos reciban el tipo de educación conforme a sus convicciones», pero esto solo implica «la libertad de elección de centro docente». Sí se menciona «la enseñanza de asignaturas del currículum en Inglés».
PP 2008

Lengua y símbolos. Principio 177: «Los españoles tienen derecho a elegir el idioma en el que educar a sus hijos». Propuesta 187: «Garantizaremos por ley el derecho a utilizar y a estudiar en castellano en todas las etapas del sistema educativo». Propuesta 188: en las Comunidades Autónomas con dos lenguas oficiales estarán garantizados «los derechos preferentes de los padres y de los alumnos, de modo que en todas las etapas educativas y en todos los cursos, la lengua castellana sea vehicular en las distintas áreas y materias, junto con la otra lengua cooficial en el marco de un modelo de bilingüismo integrador».

Hay que reconocer que no está muy claro si en el programa de 2008 el PP abrazaba el separatismo lingüístico o no (es decir, la alternativa 1). El separatismo parece seguirse del principio 177 y la propuesta 187, pero la redacción de la propuesta 188 hace pensar más en un modelo de dos lenguas vehiculares.

Después de las elecciones, el Grupo Parlamentario Popular del Congreso se apresuró a presentar una Proposición no de Ley para garantizar el principio de 
igualdad, cuyo primer apartado era una transposición de la propuesta 187 del programa electoral del partido y no terminaba de aclarar las $\operatorname{cosas}^{12}$ :

Todos los ciudadanos tienen derecho a utilizar y estudiar en castellano en todas las etapas del sistema educativo, y se garantiza un bilingüismo equilibrado e integrador en las Comunidades Autónomas que tengan lengua cooficial, de tal modo que la lengua sea un instrumento de libertad y solidaridad al servicio de las personas, un vehículo de entendimiento y nunca una fuente de desigualdades.

En este punto se produjo una réplica del «efecto UPyD» que podríamos denominar «efecto Manifiesto». Después de la publicación, auspiciada por UPyD, del Manifiesto por la lengua común (verano de 2008), el pP volvió a llevar la cuestión lingüística al Congreso, esta vez con una Proposición de Ley Orgánica de modificación de la Ley Orgánica de Educación, para garantizar la enseñanza del castellano y en castellano en todas las etapas educativas ${ }^{13}$, que contiene un cruce de nuestras dos alternativas. Más allá de las "primeras enseñanzas», que debían dispensarse en la lengua habitual del alumno, por un lado (6 ter. 3) se apuntaba a un modelo en que la lengua castellana sea ofrecida como lengua vehicular junto con la otra lengua oficial (alternativa 2), pero por el otro (6 ter. 4) se insistía en la opción de recibir las enseñanzas exclusivamente en castellano (alternativa 1). En otras palabras, la vehicularidad del castellano primaba sobre la libertad de elección, puesto que se sugería un modelo con solo dos opciones: todo en castellano o bilingüe, sin opción para una enseñanza con la LP como única lengua vehicular. De este modo, la Proposición nos situaba en un escenario no de ES=LP sino claramente de ES>LP.

Artículo 6 bis. Garantía de la enseñanza del castellano y de su uso como lengua vehicular.

1. Las administraciones educativas garantizarán el derecho de los escolares a recibir las enseñanzas en castellano, lengua oficial del Estado, en todas las etapas educativas. En las comunidades autónomas que, junto al castellano, tengan otra lengua oficial, de acuerdo con sus estatutos, el ejercido de este derecho se ajustará a las reglas enunciadas en el artículo siguiente.

12 Esta iniciativa fue rechazada el 8 de mayo de 2008.

${ }^{13}$ Esta iniciativa fue rechazada el 28 de abril de 2009. 
Artículo 6 ter. Normas especiales para las comunidades autónomas con otra lengua cooficial. 2. Los niños tienen derecho a recibir sus primeras enseñanzas, tanto en la educación infantil como en la educación primaria, en su lengua habitual, ya sea ésta el castellano o la otra lengua cooficial de la Comunidad Autónoma. Las administraciones educativas han de garantizar este derecho y poner los medios necesarios para hacerlo efectivo.

3. Las administraciones educativas garantizarán que en todas las etapas educativas y en todos los cursos la lengua oficial del Estado sea ofrecida como lengua vehicular en las distintas áreas y materias junto con la otra lengua cooficial, en su caso, en proporciones equilibradas en el número de horas lectivas, de manera que se procure el dominio de ambas lenguas oficiales, sin perjuicio de la posibilidad de incluir una lengua extranjera. 4. No obstante lo dispuesto en el apartado anterior, se garantizará la opción de recibir las enseñanzas en castellano, atendiendo los derechos preferentes de los padres y de los alumnos, sin perjuicio del aprendizaje de la otra lengua cooficial en los términos que establezca la legislación de la Comunidad Autónoma. Para hacer efectivo este derecho, las administraciones educativas podrán establecer una planificación de la oferta escolar, que tendrá en cuenta la realidad sociolingüística del entorno educativo y la población castellano hablante.

Para complicarlo un poco más, la proposición preveía que la opción de recibir las enseñanzas en castellano no se ejerciera en centros separados: «6. Las administraciones educativas establecerán las medidas oportunas para procurar que los alumnos no sean separados en centros distintos por razón de su lengua habitual».

Quien sí abrazó claramente el separatismo fue precisamente UPyD, que en su programa para las elecciones españolas de 2008 postulaba el derecho de padres y alumnos a escoger la lengua que prefieran «a lo largo de la escolarización». UPyD concretó su propuesta en una Proposición de Ley Orgánica para prevenir y erradicar la discriminación lingüística y asegurar la libertad de elección de lengua presentada poco después de las elecciones ${ }^{14}$. Véanse los artículos 4.1 y 6.6 de esta Proposición:

4.1. Los servicios sociales básicos, la sanidad y los demás servicios públicos, ofrecerán atención en las lenguas oficiales de las Comunidades Autónomas bilingües. La educa-

${ }^{14}$ Esta iniciativa fue rechazada el 17 de marzo de 2009. 
ción, en todos sus niveles, ofrecerá itinerarios educativos en esas lenguas. Siempre se permitirá el ejercicio efectivo de la elección lingüística.

6.6. El sistema público de enseñanza obligatoria garantizará en todos los casos el derecho a la escolarización en castellano y a la adecuada enseñanza y aprendizaje de la lengua cooficial. En cualquier caso, todos los niños tendrán garantizado el derecho a la escolarización en su lengua materna y al aprendizaje de la lengua cooficial.

(Cabe señalar la posible contradicción entre este redactado y la posición expresada en el Manifiesto. Aquí, «el derecho a la escolarización en lengua materna» sugiere una posible escolarización exclusiva en una lengua diferente del castellano; el Manifiesto, en cambio, sugiere que las «lenguas cooficiales autonómicas» nunca pueden figurar en los planes de estudio, ni siquiera en un contexto de libertad de elección, como lengua vehicular exclusiva).

En este contexto, la posición del Partido Popular de Galicia [PPdeG] no es especialmente más nítida que la del PP nacional. En su programa para las elecciones autonómicas de 2009, el PPdeG mostraba su claro rechazo al Decreto $124 / 2007$, pero no apostaba claramente por un modelo separatista basado en la libertad de elección, sino más bien por nuestra alternativa 2 .

No ámbito educativo: derrogaremos o Decreto de Fomento do uso do Galego na ensinanza do Bipartito, propiciando un amplo consenso para aprobar unha nova norma que permita:

[...]

Garantir que se respecte o dereito dos pais e dos nenos a elixir cal é a lingua materna dos seus fillos; e garantir que todos os alumnos sexan acollidos no sistema educativo na súa lingua materna, e introducidos progresivamente na outra lingua oficial.

[...]

Garantir o equilibrio e proporcionalidade nas materias que se imparten en galego e castelán no sistema educativo, permitindo a necesaria flexibilidade. Previamente a Administración escoitará a través de procedementos regrados a opinión dos pais en relación coas materias que se impartirán en cada idioma.

Esta proporcionalidade estenderase aos centros trilingües nos que se tentará que $1 / 3$ das horas de docencia se impartan nas tres linguas vehiculares: castelán, galego e inglés. 


\subsection{El caso de la Administración pública}

La polémica sobre la educación nos abre la puerta a nuestra siguiente controversia. Aquí esbozaremos brevemente la cuestión de los usos lingüísticos de la Administración y de los requisitos lingüísticos exigibles para trabajar en su seno.

Más allá de la cuestión de la lengua vehicular, la normalización lingüística en el ámbito educativo ha llevado a las lenguas propias de las comunidades autónomas relevantes a convertirse en la lengua habitual de la Administración educativa, de la misma manera que lo son, de un modo general, en la Administración autonómica y local.

Por lo que respecta a la Administración autonómica y local, véase el artículo 5 de la Ley de normalización lingüística en Cataluña ${ }^{15}$ :

1. El català, com a llengua pròpia de Catalunya, ho és també de la Generalitat i de l'Administració local i de les altres corporacions públiques dependents de la Generalitat.

2. El català i el castellà, com a llengües oficials a Catalunya, hi han d'ésser emprats preceptivament per l'Administració en la forma determinada per la llei.

Para el uso del catalán y del castellano «en la formada determinada por la ley» debe consultarse el Decreto 107/198716. Según este Decreto, de una manera «general» la Administración autonómica de Cataluña utilizará el catalán, con solo dos posibles excepciones: la documentación destinada a administraciones públicas o a personas físicas o jurídicas de fuera del ámbito lingüístico catalán y la documentación destinada a personas físicas o jurídicas residentes en este ámbito que la soliciten expresamente en castellano.

En el caso específico de la educación, la misma Ley de normalización lingüística ya estableció en su artículo 20 que «els centres d'ensenyament han de fer de la llengua catalana vehicle d'expressió normal, tant en les activitats internes, incloent-hi les de caràcter administratiu, com en les de projecció externa».

${ }^{15}$ Llei 7/1983, de 18 d'abril, de normalització lingüística a Catalunya.

16 Decret 107/1987, de 13 de març, pel qual es regula l'ús de les llengües oficials per part de l'Administració de la Generalitat de Catalunya. 
Y la Ley también previó de modo pionero un doble requisito lingüístico para los profesionales de la enseñanza. En su artículo 18, la Ley establecía que «D’acord amb les exigències de llur tasca docent, els professors han de conèixer les dues llengües oficials».

(Nótese la formulación mucho más suave del artículo 17 de la Ley gallega: «Nas Escolas Universitarias e demais centros de Formación do Profesorado será obrigatorio o estudio da lingua galega. Os alumnos destes centros deberán adquiri-la capacitación necesaria para facer efectivos os dereitos que se amparan na presente Lei»).

Ahora se trataría de rastrear también las alternativas a este modelo de lengua-preferente-con-requisito-lingüístico-universal. En este sentido, el partido que ha abanderado con mayor vehemencia la oposición al modelo es UPyD.

Ya en el Manifiesto por la lengua común se recomienda la rotulación y la documentación bilingües y se rechaza de modo explícito que se expresen únicamente «en lengua autonómica»; también se rechaza el requisito lingüístico universal:

En las autonomías bilingües, cualquier ciudadano español tiene derecho a ser ATENDIDO INSTITUCIONALMENTE EN LAS DOS LENGUAS OfICIALES. Lo cual implica que en los centros oficiales habrá siempre personal capacitado para ello, no que todo funcionario deba tener tal capacitación.

Por lo que respecta a los usos lingüísticos de la Administración, en su Proposición de Ley Orgánica antes mencionada, UPyD apuesta por una suerte de «bilingüismo por defecto»:

4.4. En los tratos con los ciudadanos y las personas jurídicas, las Administraciones públicas presentes en las Comunidades bilingües, y las instituciones que de ellas dependan, asegurarán en todos los casos, sin excepciones, la comunicación ordinaria en ambas lenguas oficiales, en cualquier soporte y medio, sin otro requisito ni petición por parte de los ciudadanos.

6.2. Los Poderes Públicos velarán por la observancia del bilingüismo en todos los espacios públicos de las Comunidades Autónomas bilingües, tanto físicos como virtuales, incluyendo la totalidad de los rótulos, instrucciones, formularios, impresos, señalizacio- 
nes, avisos y cualquier otra forma pública de comunicación en cualquier formato o soporte.

Sin embargo, al establecer el uso obligatorio del castellano en la documentación, el texto de la Proposición se desliza de este modelo LP = ES a un modelo ES > LP, que corre el riesgo incluso de vaciar de contenido a la oficialidad de LP:

6.3. Todas las Administraciones públicas de todos los niveles territoriales redactarán toda su documentación al menos en castellano. En las Comunidades Autónomas con lengua cooficial se incluirá la versión en dicha lengua. En ningún caso se tendrá por válido en España ningún documento público que no cuente con una versión en castellano.

Por otra parte, la Proposición también rechaza el requisito lingüístico universal en términos parecidos a los del Manifiesto:

4.3. El conocimiento de la lengua cooficial de la Comunidad sólo podrá ser exigido, como requisito para acceder a un empleo público, relacionarse con las Administraciones públicas o desarrollar alguna actividad, cuando las funciones inherentes al puesto de trabajo o la naturaleza de la relación o actividad a desarrollar conlleven de modo inseparable el uso imprescindible de la lengua cooficial. En los demás casos, sólo podrá valorarse como un mérito no excluyente.

6.5. Las Administraciones públicas no podrán exigir el conocimiento de una lengua oficial distinta del castellano como requisito para el acceso a las funciones públicas, sin perjuicio de que pueda valorarse como un mérito de forma proporcionada, salvo en aquellos casos concretos donde constituya un requisito imprescindible por la naturaleza de la función pública encomendada.

El rechazo del modelo también es visible en el programa de UPyD para las elecciones gallegas de 2009. Por un lado, se postula el «bilingüismo por defecto»:

Proponemos que todos los anuncios, informaciones y señalizaciones de los organismos públicos de Galicia o instituciones sostenidas con fondos públicos estén redactados en las dos lenguas cooficiales, al igual que todos los impresos. Esto incluye instituciones culturales sostenidas con fondos públicos. 
Por el otro, se rechaza el requisito lingüístico:

[Proponemos] la derogación del artículo 35 del Decreto Legislativo 1/2008, de 13 marzo, que aprueba el texto refundido de la Ley de la función pública de Galicia, en cuanto impone la obligación de demostrar el conocimiento de la lengua gallega en todas las pruebas selectivas que se realicen para el acceso a las plazas de la Administración de la Comunidad Autónoma y en las entidades locales. Proponemos la presencia en la Administración de personal de habla gallega dentro del conjunto de funcionarios a los que corresponda un determinado servicio, como modo de garantizar el derecho a usar esta lengua cooficial por parte de los ciudadanos que lo deseen, sin que el conocimiento de dicha lengua pueda en ningún caso exigirse como requisito excluyente o valorarse de forma desproporcionada frente a la capacidad, conocimientos e idoneidad exigibles para el desempeño de las funciones concretas que sean competencia de la plaza que pretenda cubrirse.

El pP no ha tratado el asunto con la misma intensidad. En el programa de 2008 figura el desafío 179, que sugiere implícitamente la existencia del requisito lingüístico en algunas comunidades autónomas: «La lengua no puede convertirse en un factor de discriminación ni una barrera cultural para restringir derechos, impedir la movilidad geográfica, o romper la unidad de mercado».

Pero este desafío no conlleva ninguna propuesta de suprimir tal requisito. Y tampoco se observan propuestas sobre los usos lingüísticos de la Administración en general. En el caso del PPC y del PPdeG tampoco se observan posiciones favorables a la supresión sin más del requisito lingüístico universal. Si UPyD proponía la simple derogación del artículo 35 del Decreto Legislativo 1/2008, lo que ha dispuesto el PPdeG, como ustedes saben, es su reforma en los términos siguientes (Vid. tabla 9). 
- Tabla 9. Comparación entre la formulación del requisito lingüístico antes y después de la reforma

Formulación anterior a las elecciones

Para lle dar cumprimento á normalización do idioma galego na Administración pública de Galicia e para garantir o dereito das administradas e dos administrados ao uso da lingua propia de Galicia nas relacións coa Administración pública no ámbito da comunidade autónoma, e en cumprimento da obriga de promover o uso normal do galego por parte dos poderes públicos de Galicia que determina o artigo $6.3^{\circ}$ da Lei de normalización lingüística, nas probas selectivas que se realicen para o acceso ás prazas da Administración da Comunidade Autónoma de Galicia, e nas entidades locais de Galicia, terase que demostrar o coñecemento da lingua galega.

Para estes efectos, as bases das convocatorias establecerán que unha ou máis das probas do proceso selectivo se deberán realizar exclusivamente en lingua galega, e iso sen prexuízo doutras probas adicionais, que se puidesen prever, para aqueles postos de traballo que requiran un especial coñecemento da lingua galega.
Formulación según la Ley 2/2009

Para lle dar cumprimento á normalización do idioma galego na Administración pública de Galicia e para garantir o dereito das administradas e dos administrados ao uso do galego nas relacións coa Administración pública no ámbito da comunidade autónoma, e a promoción do uso normal do galego por parte dos poderes públicos de Galicia, que determina o artigo $6.3^{\circ}$ da Lei de normalización lingüística, nas probas selectivas que se realicen para o acceso ás prazas da Administración da Comunidade Autónoma de Galicia e das entidades locais de Galicia incluirase un exame de galego, agás para aqueles que acrediten o coñecemento da lingua galega conforme a normativa vixente. As bases das convocatorias dos procesos selectivos establecerán o carácter e a valoración deste exame. Todo isto sen prexuízo daquelas probas que teñan que realizarse en galego para aquelas prazas que requiran un especial coñecemento da lingua galega.

En el caso del PPC, su programa para las elecciones catalanas de 2003 proponía «invertir la exigencia previa del conocimiento de la lengua con una política de fomento del conocimiento posterior", pero no se conocen iniciativas legislativas de este partido que concreten la modalidad de esta inversión. 


\section{3. ¿ES POSIBLE EL CONSENSO?}

Como he dicho al comienzo, para terminar me gustaría valorar brevemente las posibilidades de alcanzar el consenso en las dos áreas de controversia identificadas, que quedan resumidas en la tabla 10.

- Tabla 10. Comparación entre las posiciones de la interpretación 1 y la interpretación 2

\begin{tabular}{|c|c|c|}
\hline & Interpretación 1 & Interpretación 2 \\
\hline & LP $>$ ES & $\mathrm{LP}=\mathrm{ES}$ \\
\hline \multirow[t]{7}{*}{ Educación } & LP única lengua vehicular & Alternativa 1: Libertad \\
\hline & & de elección que incluya \\
\hline & & la opción es única lengua \\
\hline & & vehicular (y no siempre \\
\hline & & la opción LP) \\
\hline & & Alternativa 2: $\mathrm{LP}+\mathrm{ES}$ \\
\hline & & lenguas vehiculares \\
\hline \multirow[t]{2}{*}{ Administración } & LP uso preferente & LP + ES por defecto (o solo ES) \\
\hline & LP requisito universal & LP mérito \\
\hline
\end{tabular}

A primera vista, las posiciones parecen irreconciliables. Fijémonos primero en el caso de la educación. Si la lengua propia de la comunidad autónoma debe ser la única lengua vehicular para todos los alumnos no es posible que los alumnos elijan la lengua vehicular, y si los alumnos eligen como lengua vehicular la lengua propia no podrá ser la única lengua vehicular para todos los alumnos. Solo hay dos maneras de salir de ahí. Una posibilidad es consagrar simplemente el modelo que prefiere la mayoría política; en Cataluña la mayoría de actores políticos (118 diputados sobre 135, para entendernos) apuesta por el catalán como lengua vehicular para todos los alumnos. En Galicia hay una mayoría (ciertamente exigua: 38 sobre 75) que al parecer apuesta por un modelo alternativo. Pero existe una segunda posibilidad, que es cambiar los términos del debate. Si en lugar de fijarnos en la lengua vehicular nos fijamos en los objetivos del sistema educativo, hay lugar para el acuerdo entre la mayoría y la mino- 
ría. En Cataluña, por ejemplo, todas las propuestas críticas que se han lanzado desde 1981 para acá contra el principio del catalán como lengua vehicular han asumido siempre que los alumnos deben aprender las dos lenguas oficiales.

Pues bien, una manera de disolver el debate estaría en fijar, escuela por escuela, la(s) lengua(s) vehicular(es) en función de ese objetivo. El resultado sería que no habría una sola lengua vehicular para todos los alumnos pero tampoco libertad de elección de la lengua vehicular; más bien tendríamos un amplio espectro teórico de casos, desde la escuela en que el 100\% de las materias se imparten en LP en todos los niveles hasta la escuela en que el 100\% de las materias se imparten en ES en todos los niveles, con la única condición de que se garantice el bilingüismo terminal.

Si ahora nos fijamos en el caso de la Administración, la reflexión es parecida. Si la lengua propia de la comunidad autónoma debe ser la lengua «normal i preferent» de la Administración no es posible que la Administración practique habitualmente el uso de las dos lenguas oficiales, y si la Administración practica habitualmente ese uso no podrá tener la lengua propia de la comunidad como lengua «normal i preferent». Como antes, hay dos maneras de salir de ahí: o la mayoría absoluta o un cambio en los términos del debate. Si en lugar de fijarnos en la(s) lengua(s) por defecto de la Administración nos fijamos en los derechos lingüísticos de los administrados, también aquí hay lugar para el acuerdo. En 1995 el PPC prometía garantizar «el uso de las dos lenguas en el ámbito de la Administración autonómica, local y estatal para que las instituciones aseguren a todos los ciudadanos el uso de cualquiera de las lenguas oficiales». Aquí, de nuevo, para disolver la polémica se trataría de fijar, Administración por Administración, la(s) lengua(s) de comunicación que de(n) mayor respaldo a esos derechos lingüísticos. Un «concello» en el que todos los administrados prefieren comunicarse en gallego, por ejemplo, podría hacer un uso exclusivo del gallego en su documentación, y al revés, siempre que se garantice el derecho de los posibles discrepantes a ser atendidos en la otra lengua oficial.

Por lo que respecta al requisito lingüístico, habría que hacer una operación parecida. Más que el requisito en sí lo que importa es qué derechos lingüísticos va a garantizar y modularlo a partir de ahí. Es posible que no en todos los casos sea necesario acreditar el mismo nivel de conocimiento de la lengua propia de la comunidad o acreditarlo en el mismo momento. Y por otra parte sería pruden- 
te empezar a hablar no de un requisito de gallego, o de catalán (o de la lengua propia correspondiente), sino de un requisito de bilingüismo, donde el conocimiento del castellano también sea requerido explícitamente y cuente con los mismos posibles atenuantes de nivel exigido y momento de la acreditación.

El resultado de esta breve reflexión es altamente revisionista y muy descorazonador para los que reducen su política lingüística a eslóganes digamos westfalianos del tipo «en España en español» o «en Galiza en galego». En otras palabras, para que los acuerdos sean posibles en política lingüística no solo hay que «subtraer a cuestión da lingua da confrontación partidaria», como pedía Subiela (2002: 169), sino que probablemente hay que renunciar a la tesis (nacionalista) de la lengua como trabazón de la comunidad política. En otras palabras, es probable que en una comunidad plurilingüe que quiere seguir siendo plurilingüe (léase Galicia, pero también España) una sola lengua no pueda ser, contrariamente a lo que dice el antiguo Decreto 247/1995, que ustedes conocen bien, «o máis forte vencello de unión entre as súas xentes». 


\section{BIBLIOGRAFÍA}

Marcía Marcos, F. J.: Bases de planificación lingüistica para Andalucía, Almería, Universidad de Almería, 2008.

Monteagudo, H.: "A lingua galega na sociedade: descrición da situación actual e perspectivas de futuro", en H. Monteagudo et al., A normalización lingüistica a debate, Vigo, Edicións Xerais, 2002.

SubielA, X.: «Política lingüística en Galicia», en H. Monteagudo et al., A normalización lingüistica a debate, Vigo, Edicións Xerais, 2002.

TrudgiLl, P.: A Glossary of Sociolingüistics, Edinburgh, Edinburgh University Press, 2003.

VAllverdú, F.: El conflicto lingüistico en Cataluña: historia y presente, Barcelona, Ediciones Península, 1981. 
